\title{
Ehsan Ahmed, Francis I and the Body Natural
}

\section{Filippo Fonio}

\section{(2) OpenEdition}

\section{Journals}

\section{Edizione digitale}

URL: http://journals.openedition.org/studifrancesi/35858

DOI: 10.4000/studifrancesi.35858

ISSN: 2427-5856

\section{Editore}

Rosenberg \& Sellier

\section{Edizione cartacea}

Data di pubblicazione: 1 juillet 2005

Paginazione: 144-145

ISSN: 0039-2944

\section{Notizia bibliografica digitale}

Filippo Fonio, «Ehsan Ahmed, Francis I and the Body Natural», Studi Francesi [Online], 145 (XLIX | I) |

2005, online dal 30 novembre 2015, consultato il 18 avril 2021. URL: http://journals.openedition.org/ studifrancesi/35858 ; DOI: https://doi.org/10.4000/studifrancesi.35858

\section{Questo documento è stato generato automaticamente il 18 avril 2021.}

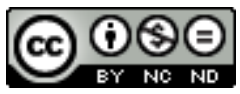

Studi Francesi è distribuita con Licenza Creative Commons Attribuzione - Non commerciale - Non opere derivate 4.0 Internazionale. 


\title{
Ehsan Ahmed, Francis I and the Body Natural
}

\author{
Filippo Fonio
}

\section{NOTIZIA}

EHSAN AHMED, Francis I and the Body Natural, «Bibliothèque d'Humanisme et Renaissance», LXV, 3 (2003), pp. 589-599.

1 L'analisi di Ehsan Ahmed mostra un esempio dell'accostamento fra natural body e mystical body nella poesia del regno di François I, con particolare attenzione alle composizioni attribuite al sovrano. Un primo movimento della figura poetica è costituito dall'utilizzo del rimando tipologico che vede nel Valois un nuovo re Davide, come ad esempio in Guillaume Michel de Tours, Le Penser de royal mémoire (1518), un'esortazione al monarca a intraprendere una crociata contro i Turchi, oppure nell'epistola dedicatoria a François I composta da Clément Marot per i suoi Cinquante pseaumes de David... (1541), dove il poeta sviluppa nel contempo l'analogia fra François e Davide e il motivo tradizionale di Davide figura Christi. Marguerite de Navarre riprende questi motivi in un'epistola in versi del 1543 indirizzata al fratello, alla quale François replica dichiarandosi indegno di un accostamento con il re Davide proprio in quanto profondamente immerso nella dimensione del suo corpo naturale, nell'incostanza delle passioni umane. Nella lirica composta dal Valois si trovano diverse variazioni sul tema petrarchesco del fuoco della passione - segno dell'imperfezione umana in quanto prepotente affermazione del natural body - oltre alla ricorrente allegoria della salamandra che nasce e vive nel fuoco. Interessante notare come proprio l'immagine della salamandra venga ripresa in una lettera di Guillaume Briçonnet del 1521 a Marguerite d'Angoulême, dove le salamandre sono due come due sono i fuochi, uno legittimo anzi auspicabile e uno diabolico. 